Scotland, which is greatly enhanced by lavish colour illustrations. The very evident enthusiasm of the authors for the areas which they cover has permitted the book to capture the excitement of ecological research and both amateur and professional will find much that is new and little that is dull.

T.H. CLUTTON-BROCK

\title{
Flora Europaea, Vol. 5, edited by T.G. Tutin et al. Cambridge UP, £37.50.
}

With the publication of this fifth volume one of the most important recent taxonomic projects has been completed. Anyone who needs to be able to name plants in Europe can be grateful to the team of authors who have put together this magnum opus. It is a relief to the professional botanist to be able to quote a source for nomenclature and taxonomy that will be accepted as standard by all other workers.

Volume 5 covers the whole of the Monocotyledons from Alismataceae to Orchidaceae. The gross taxonomy will not cause any surprises, but at the generic and specific levels the lumpers, splitters and name-droppers have been at work. I was certainly pleased to see Scirpus re-embrace Bolboschoenus, Holoschoenus, Isolepis, Schoenoplectus, and Trichophorum. In the Gramineae, however, the nomenclature caused me some problems. The genus Festuca is a minefield for unwary botanists, but using Flora Europaea I was not wholly able to sort out the nomenclature of what used to be $F$. cinerea and $F$. glauca, and the lists of synonyms provided do not seem to be sufficiently comprehensive.

Perhaps the authors can be forgiven for leaving Festuca as complex as its biological reality, but a few pages further came a greater shock. At first I thought the genus Leymus was an improbable misprint for Elymus, but $E$. arenarius has in fact become $L$. arenarius. The genus Elymus still exists and it contains all the familiar species of Agropyron - that genus now comprises a few species in central Asia!

Clearly any new flora will bring forward nomenclatural changes like this, and doubtless contemporaries castigated Bentham and Hooker for the same reason. Gradually the new names will come to be accepted (or will they? - I have to confess to still using the old 'unsplit' genus Lycopodium, and Volume 1 appeared in 1964), but when one bears in mind the necessary element of artificiality in any system of biological classification, changes such as those in Agropyron and Elymus require powerful justification. I fear it will still be Agropyron repens that I dig up from my garden for a few years yet.

Nevertheless, as a whole Flora Europaea has been characterised by nomenclatural restraint and has proved taxonomically robust. It has stimulated much valuable taxonomic research and radically altered our conception of the flora of Europe. Reference works can become standards either because so little is known about the field that the mere existence of the work gives it a necessary authority, or because the treatment is so exhaustive that it can be relied upon to be accurate. Flora Europaea fits the second category.

A.H. FITTER

The Private Life of the Otter, by Philip Wayre. Batsford, £4.95.

The meat of this book is in the delightful and informative first six chapters on the otter's natural history. They provide a unique insight into the otter's private life and are illustrated with the author's excellent photographs. The book's title is misleading, however, since three chapters are largely devoted to the otter's public life at the Otter Trust - which is interesting enough, but not without padding: for example, a detailed account of exactly how the otter pens at the Otter Trust are constructed.

The chaper on otter conservation is notable for its omissions rather than its content. On page 81 Philip Way re says "it is to the landowner that we must look for the survival of the otter over large areas of Britain', and yet there is no mention of the county 
naturalists' trusts or the Otter Haven Project's work in this field. More too could have been said about the way in which the water authorities' schemes affect otter habitat, the opportunities which exist to reconcile the needs of land drainage and wildlife conservation, and the initiatives which some water authorities (for example, the Wessex and Welsh) have already taken. I am slightly uneasy about teaching the general public how to search for otter signs (chapter 10); increased disturbance was mentioned in chapter 9 as a possible reason for the otter's decline, and further disturbance by well-meaning otter-watchers may not be desirable.

Philip Wayre's achievements in breeding otters in captivity are unsurpassed, and he writes about his work with an infectious enthusiasm. This is a fascinating introduction to otters, but could have given more information about the animal's conservation.

ANGELA KING

\section{A Wood in Ascam: a Study in Wetland Conservation, edited by A.H. Fitter and C.J. Smith. Ebor Press, York, and Yorkshire Naturalists’ Trust, £4.95.}

This small volume records the history and present ecology of 'the Wicken Fen of the North', the 100-acre Askham Bog just two miles from the centre of York. The first hundred pages are occupied by chapters dealing with the history of the area, its habitats and its flora, with selected animal groups and with current management. None of the chapters dealing with the flora and fauna attempts to be comprehensive; instead special attention is paid to groups or species of particular interest. The chapters on history, habitats and plants contain much astute observation and summaries of a considerable amount of recent research. The final third of the book is given over to appendices listing species recorded on the bog. Unfortunately there is no index.

The book was produced to commemorate the centenary of the publication, in 1879 , of the first systematic account of the biology of the area. The desire to meet this deadline is perhaps reflected in a degree of repetition, some roughness of style and poor collation between some sections. Immediate contrasts suggest themselves between this book and the monographs on Hayley Wood and Monk's Wood, both of which also seem to be aimed at the interested amateur and the professional. The smaller size of the present volume inevitably means less complete coverage, while the general standard of production, especially of figures, is lower. Within such limitations however this book compares quite favourably to the other two studies.

Despite some weaknesses the book will be of great interest to many conservationists, both as a record of a particular site and as an impressive indication of the observation and research needed to understand and adequately manage nature reserves.

H.J. HARVEY

\section{Population Ecology of Raptors, by Ian Newton. Poyser, $£ 10.80$.}

By synthesising studies on diurnal birds of prey world-wide this book fills a gap in the review literature. Its 18 chapters range from mating systems, dispersion, aspects of breeding and movements (including migration), through to conservation management and captive rearing. The pesticide problem and other anthropogenic issues are given three chapters - appropriately, since the identification, analysis, and amelioration of the pesticide problem has become something of a classic success for the role of science in wildlife management. Photographs are well chosen and reproduced, and a fine line drawing by Jim Gammie heads each chapter. Tables are relegated to an appendix. The style is highly readable as well as scholarly.

After a short introduction to raptor biology, the discussion begins with sex ratios and dimorphism. Breeding density - conventionally the focus of population ecology - is dealt with as early as chapter 3 . The central theme concerns the role of food, and by the final chapter it is not surprising to read the "overall conclusion that, in the absence of human intervention, almost every aspect of the natural population ecology of a given 